\title{
Enhance the Telecommunication Services based on the Location of Users
}

\author{
Saher Manaseer \\ Computer Science \\ Department \\ King Abdullah II School \\ for Information \\ Technology, The \\ University of Jordan, \\ Amman, Jordan
}

\author{
Nabeel Alassaf \\ Computer Science \\ Department \\ King Abdullah II School \\ for Information \\ Technology, The \\ University of Jordan, \\ Amman, Jordan
}

\author{
Mohammad Almasri \\ Computer Science \\ Department \\ King Abdullah II School \\ for Information \\ Technology, The \\ University of Jordan, \\ Amman, Jordan
}

\author{
Baker Alhassan \\ Computer Science \\ Department \\ King Abdullah II School \\ for Information \\ Technology, The \\ University of Jordan, \\ Amman, Jordan
}

\begin{abstract}
Due to the increase in the number of telecommunications companies, the competition increases as well in providing best services and keeping customers loyal to the company. This paper uses data collected based on location by a telecommunication company in Jordan, and analyse the data to find suggestions for enhancing the services provided to customers in the locations that have few users and for institutions and companies. The real data of the selected telecommunications company is statistically analyzed and new techniques and suggestions were proposed to improve the services provided them in terms of Speed of ADSL lines and increase the download for Subscriptions.
\end{abstract}

\section{Keywords}

Location Based Services, Internet Services, ADSL, Quality of Service.

\section{INTRODUCTION}

The information of Locations has gained a significant importance in the first world war, for military purposes especially for submarines. After that the concept has developed and integrated to the smart technologies. All sectors now benefit from the location based services to enhance their production and sales. Such services based on location needs network connection, positioning system, servers. [1][6]

Recently, most of the location based services are available through the applications store on smart devices, where any user can use them, by sending the request through the application to the server [2]. Those services are used in many applications, such as requesting cars and taxi, online shopping, delivery of some goods, and many other applications.

Yet, the privacy of the users' location is a challenge for such applications. Such as location and other data of the user, which making tracking users easier for hackers and leakers [3] [4] [5].

This paper contributes to enhance the provided services by tele-communication companies, real data is collected from the three main providers of telecommunication companies in Jordan, one of them was selected for the purpose of this paper, but the name is hidden as requested since the data shown is real, and the company asked for not explicitly mentioning its name. Data is analyzed and results were discussed to put in to implantation for helping the telecommunication companies get high performance and more benefits.

\section{METHODOLOGY}

To select the sample, four main cities were selected for the purpose of this study. Those cities are the capital Amman, Zarqa, Aqaba, and Irbid. Representing the middle (east and west), South and North of the country respectively.

Based on the gathered data from the selected telecommunication company in Jordan, the number of users receive the services from this company is limited in four cities, the highest percentage found in Zarqa, Amman, Irbid and Aqaba respectively. As figure 1 shows.

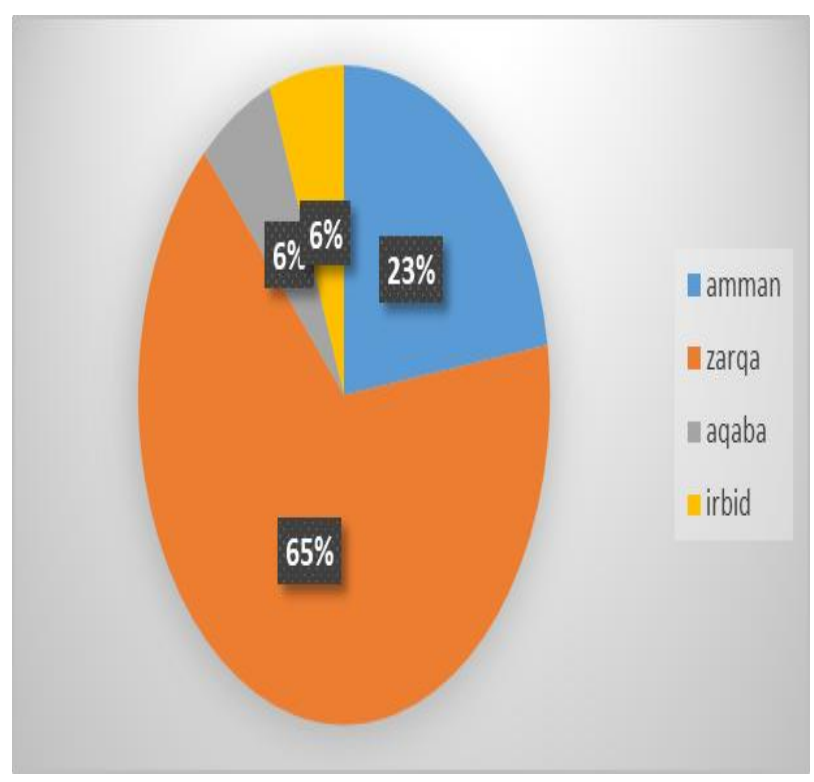

Figure 1:Number of customers in Jordanian cities

As the figure shows, the highest percent of subscribers to the company services are in Zarqa, and the lowest in Aqaba and Irbid. This bring the search for reasons behind the low percent in those cities, and trying to enhance the services if they don't satisfy the customer. To do so; the following steps were done.

First, the data of Irbid city based on speed of ADSL lines and number of users is analyzed; as shown in the figure below: 


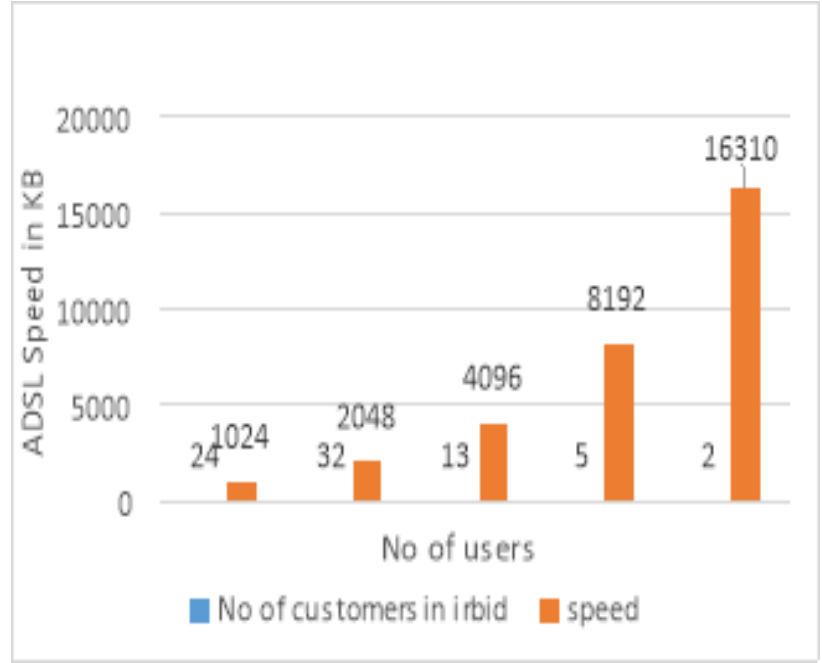

Figure 2: ADSL speed VS Number of users in Irbid city

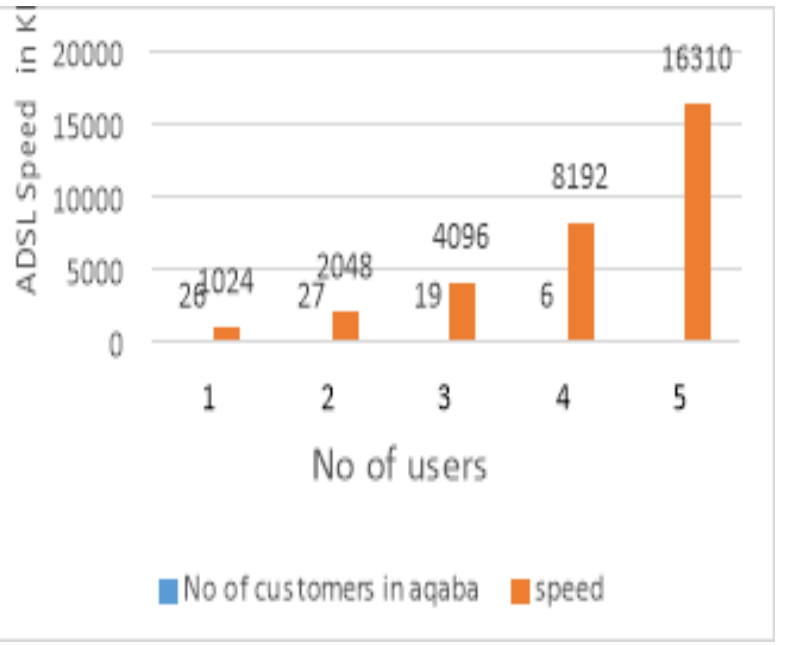

Figure 3: Speed VS Number of users in Aqaba

The results in figure 2 indicate that the number of users provided with ADSL speed service less than or equal 1024 KB, $2048 \mathrm{~KB}, 4096 \mathrm{~KB}, 8192 \mathrm{~KB}, 16310 \mathrm{~KB}$ are 24, 32, 13, 5 , and 2 respectively.

On the other hand, the results in figure 3 indicate the number of users that are provided with ADSL speed service less than or equal $1024 \mathrm{~KB}, 2048 \mathrm{~KB}, 4096 \mathrm{~KB}, 8192 \mathrm{~KB}, 16310 \mathrm{~KB}$ are $26,27,19,6$, and 0 respectively.

In order to encounter the users in this telecommunication company to still customers in this company and to obtain new customers in these cities; some of solutions were proposed in terms of providing new offers such as double the speed for the users who use $1024 \mathrm{~KB}$ or less to $2048 \mathrm{~KB}, 2048 \mathrm{~KB}$ to 4096KB and so on, without additional subscription fees. Meanwhile grant each user monthly 20 GB of download. These solutions led the users to be more loyal to this company and encourage more users to subscribe. Thus, increasing number of users in these cities.

Regarding Zarqa and Amman, they contain the highest population percent, since Amman is capital and Zarqa is the second in population, those two can increases the subscribers in the company if people find good offers such as a free month each year for those who have been subscribing for more than two years, also making offers to new subscribers through an unlimited download package for the first six months of subscription and monthly offers to customers.

On the other hand, a novel solution is proposed to provide enterprises in this telecommunication company, based on analyzing data, the largest number of enterprises concentrated in Amman and Zarqa. The company shall set a target to provide these enterprises with best internet services through increasing speed of ADSL lines and increase download without any additional fees. The figure below represents the percentage of subscriber's enterprises from zarqa and Amman.

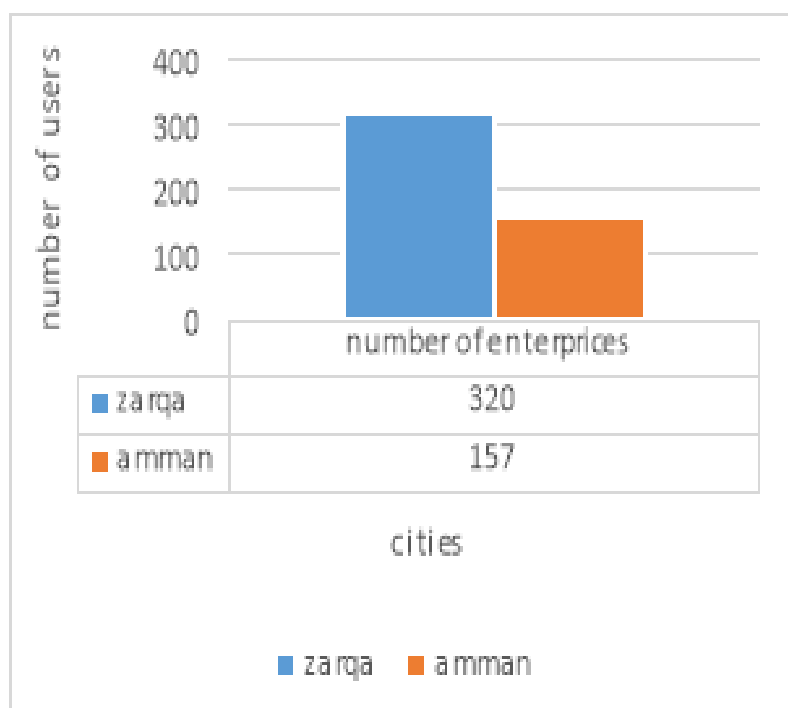

\section{Figure 4: numbers of users in Amman and Zarqa cites}

In the sense of location-based services, we focus in this section on Zarqa and Amman cities. Not only because the number of subscribers from Amman and Zarqa in this company is the largest, but also because those cities contain most of the country companies' main offices, therefore this solution will gather other companies to subscribe in this telecommunication company.

The proposed solution to provide Zarqa and Amman with best internet services represented by determination ADSL speed for enterprises, then double speed of the ADSL lines and grant each company monthly 40 GB download free, and if the enterprises used all download capacity before the end of each month, they can get additional $40 \mathrm{~GB}$ with discounts on fees, the following table shows the speeds used by companies in Amman and Zarqa.

Table 1:internet speed vs number of users

\begin{tabular}{|c|c|}
\hline Internet speed in KB & Numbers of enterprises \\
\hline 1024 & 137 \\
\hline 2048 & 163 \\
\hline 4096 & 139 \\
\hline 8192 & 37 \\
\hline
\end{tabular}




\section{CONCLUSIONS}

In this pager, real data of a telecommunication company is collected based on location services and analyzed. The company provides Internet services over 1300 subscribers in four cities, Amman, Zarqa, Irbid and Aqaba, and additional solutions and services by location were proposed to help the company to enhance its services and increase the number of subscribers as well as gain their loyalty.

Moreover, the subscribed enterprises in the city of Zarqa and Amman are studied, and more suggestions were proposed for the company to enhance services offered to those companies and enhance the process of subscriptions.

\section{REFERENCES}

[1] Kupper, A., (2005), "Location-based Services: Fundamentals and Operation”, John Wiley \& Sons, 2005

[2] B. Niu, S. Gao, F. Li, H. Li, Z. Lu, (2016) "Protection of location privacy in continuous lbss against adversaries with background information”, in: Proceedings of 2016 International Conference on Computing, Networking and Communications, 2016, pp. 1-6.

[3] R. Schlegel, C.-Y. Chow, Q. Huang, D.S. Wong (2015), User-defined privacy grid system for continuous location-based services", IEEE Trans. Mob. Comput. 14 (10) (2015) 2158-2172.

[4] E. Balandina, S. Balandin, Y. Koucheryavy, D. Mouromtsev, Innovative etourism services on top of Geo2Tag LBS platform, in: Proceedings of 11th International

[5] Conference on Signal-Image Technology \& InternetBased Systems, 2015, pp. 752-759.

[6] A. Acquisti, L. Brandimarte, G. Loewenstein, Privacy and human behavior in the age of information, Science 347 (6221) (2015) 509-514. 